2. Huang S, Li JY,W u J, Meng L, Shou CC. Mycoplasma infections and different human carcinomas. World J Gastroenterol 2001; 7: 266-269.

3. Huang S, Li JY,W u J, Meng L, Shou CC. Mycoplasma infection in human gastrointestinal carcinoma tissue. Zhonghua Yi Xue Za Zhi 2001; 81:601-604.

4. Tully JG . Current status of the Mollicutes flora of humans. Clin Infect D is 1993; 17: S2-S9.

5. Chen W, Li D, Paulus B,W ilson I, C hadwick VS. High prevalence of Mycoplasma pneumoniae in intestinal mucosal biopsies from patients with inflammatory bowel disease and controls. Dig Dis Sci 2001; 46:2529-2535.

6. Roediger W E, Macfarlane GT.A role for intestinal mycoplasmas in the aetiology of Crohn's disease? J A ppl Microbiol 2002; 92:377381

7. Kwon HJ, Kang JO, Cho SH, Kang HB, Kang $\mathrm{KA}, \mathrm{Kim} \mathrm{JK}$ et al. Presence of human mycoplasma DNA in gastric tissue samples from Korean chronic gastritis patients. C ancer Sci 2004; 95:311-315.

8. Pignatelli B, Bancel B, Plummer M,Toyokuni S, Patricot LM, O hshima $\mathrm{H}$. Helicobacter pylori eradication attenuates oxidative stress in human gastric mucosa. Am J Gastroenterol 2001; 96:1758-1766.

9. Rottem S. Interaction of mycoplasmas with host cells. Physiol Rev 2003; 83:417-432.

\section{Aclaración en torno al artículo sobre diarrea y tipo de lactancia}

Señor editor: nos dirigimos a usted para hacer una aclaración acerca de nuestro trabajo Lactancia materna e incidencia de diarrea aguda en los primeros tres meses de vida, aparecido en el número 1 del volumen 47 de esta revista. ${ }^{1}$ Nos hemos percatado de que algunos de los datos que aparecen en el artículo no son correctos, error del cual el grupo de autores asumimos plena responsabilidad.

Dicho error se ubica en la página 55 y abarca los renglones 12 a 15 del segundo párrafo de la primera columna, donde dice:

[...] que según los datos del cuadro $\mathrm{IV}$, tiene riesgos relativos de 1.04 (0.46-2.39) y 1.79 (0.84-3.83), respectivamente, pero cuando se carece de ambos el riesgo relativo se eleva a $2.32(1.04-5.16),[\ldots]$
Y debe decir:

[...] que según los datos del cuadro $\mathrm{IV}$, tiene riesgos relativos de 1.16 (0.49-2.75) y 1.21 (0.53-2.77), respectivamente, pero cuando se carece de ambos el riesgo relativo se eleva a $2.58(1.10-6.03),[\ldots]$

Por lo anterior, le solicitamos de la manera más atenta aceptar nuestras disculpas por no haber detectado y corregido este error en las pruebas de imprenta, y le agradeceríamos publicar la presente aclaración para el conocimiento de los lectores de esta prestigiada revista.

Reciba un saludo muy cordial.

Dr. Malaquías López Cervantes

\section{Referencias}

1. Macías-Carrillo C, Franco-Marina F, LongDunlap K, Hernández-G aytán SI, MartínezLópez Y, López-C ervantes M. Lactancia materna y diarrea aguda en los primeros tres meses de vida. Salud Publica Mex 2005;47(1):49-57. 